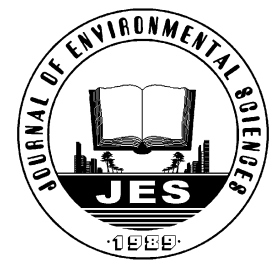

\title{
Microbial biodegradation of microcystin-RR by bacterium Sphingopyxis sp. USTB-05
}

\author{
Mulan Zhang ${ }^{1}$, Gang Pan $^{1, *}$, Hai Yan ${ }^{2}$ \\ 1. State Key Laboratory of Environmental Aquatic Chemistry, Research Center for Eco-Environmental Sciences, \\ Chinese Academy of Sciences, \\ Beijing 100085, China.E-mail: zhangmulanmine@yahoo.com.cn \\ 2. Department of Biological Science and Technology, School of Applied Science, \\ University of Science and Technology Beijing, Beijing 100083, China
}

Received 17 April 2009; revised 27 July 2009; accepted 28 August 2009

\begin{abstract}
A strain, USTB-05, isolated from Lake Dianchi, China, degraded the cyanobacterial toxin microcystin-RR (MC-RR) at the rate of $16.7 \mathrm{mg} / \mathrm{L}$ per day. Analysis of $16 \mathrm{~S}$ rDNA sequence showed that the strain was Sphingopyxis sp. Enzymatic degradation pathways for MC-RR by Sphingopyxis sp. USTB-05 were identified. Adda-Arg peptide bond of MC-RR was cleaved and then a hydrogen and a hydroxyl were combined onto the $\mathrm{NH}_{2}$ group of Adda and the carboxyl group of arginine to form a linear molecule as intermediate product within the first few hours. Then, through dehydration reaction, two hydrogen of amino group on arginine reacted with adjacent hydroxyl on carbon to form a linear MC-RR with two small peptide rings as the final product after $24 \mathrm{hr}$. These biodegradation pathways were different from those reported for other strains, implying that MC-RR may undergo different transformations and different products were formed due to various bacteria in natural lakes and reservoirs.
\end{abstract}

Key words: microcystin-RR; biodegradation; Sphingopyxis sp. USTB-05; enzymatic pathways; Lake Dianchi DOI: $10.1016 /$ S1001-0742(09)60089-9

\section{Introduction}

Toxic blooms of blue-green algae occur worldwide in eutrophic lakes, ponds and reservoirs (Paerl et al., 2001). Harmful algae, such as Microcystis, Anabaena, Nostoc and Aphanizomenon, can produce toxins, in which microcystins (MCs) are the most commonly detected toxins. MCs are a group of cyclic heptapeptide hepatotoxins, and show hepatotoxicity and tumor-promoting activity by inhibition of protein serine/threonine phosphatases 1 and 2A (Dawson, 1998). MCs are usually retained in algal cells during the growth. These intracellular toxins are eventually released into water bodies during senescence and decomposition processes, which could cause severe health risks to animals and human beings.

MCs are chemically stable in natural water (Jones and Orr, 1994; Tsuji et al., 1994). The concentrations of MCs in many natural lakes are much less than the estimated levels produced by cyanobacteria (Tsuji et al., 1996), such as in Lake Dianchi in Yunnan Province of China, which has been hypertrophicated in recent years, and harmful algae blooms appear all year around. In previous studies, we found that algae blooms in Lake Dianchi could produce high content of MCs (Yan et al., 2002, 2004a; Zhang

\footnotetext{
* Corresponding author. E-mail: gpan@ $@$ rcees.ac.cn
}

et al., 2004), where MC-RR has the highest occurrence. However, the dissolved MCs concentration in the water of Lake Dianchi was generally low (less than $1 \mu \mathrm{g} / \mathrm{L}$ ), even when the concentration of algal cells exceeded $10^{9}$ cells $/ \mathrm{L}$ (Zhang et al., 2003; Pan et al., 2006). Several pathways have been proposed to elucidate the reduction of MCs, in which photolysis and biodegradation play important roles. Photo-degradation is important in removing the dissolved MCs (Zhang et al., 2003; Song et al., 2007). However, ultraviolet can hardly penetrate even a thin layer of colored water, let alone water containing high dense algae. Biodegradation is therefore an important process controlling the fate of MCs in natural waters (Chen et al., 2008).

The bacterial communities occurred in the water body where harmful algae blooms are common, can degrade MCs along with other organic compounds which are frequently found in the environment. The isolation and biodegradability of many pure bacterial strains, such as Sphingomonas sp., Sphingpoyxis sp., Pseudomonas aeruginosa, Paucibacter toxinivorans, Delftia acidovorans and Burkholderia sp., from Australian reservoirs, Argentinean reservoirs, Japanese lakes, Finland lakes, China lakes and Brazilian coastal lagoon, respectively have been reported (Jones et al., 1994; Takenaka and Watanabe, 1997; Ishii et al., 2004; Rapala et al., 2005; Tsuji et al., 2006; Amé 
et al., 2006; Ho et al., 2007; He et al., 2006; Lemes et al., 2008). Most of strains reported belong to genus Sphingomonas, such as 7CY, B-9, Y2, ACM-3962, CBA4 and LH21 (Jones et al., 1994; Ishii et al., 2004; Amé et al., 2006; Ho et al., 2007; Tsuji et al., 2006). Among these strains, Sphingomonas sp Y2 has the highest degradation rate $(13.0 \mathrm{mg} / \mathrm{L}$ per day) for microcystin-RR (MC-RR) (Park et al., 2001).

To understand the biodegradation pathways for MC$\mathrm{RR}$, the previous studies focused on the biodegradation pathways of Sphingomonas sp. B-9 and Sphingomonas sp. CBA4. Sphingomonas sp. B-9 degraded MC-RR by cleaving the Adda-arginine peptide bond and the cycled structure was turned into linear as intermediate product. Then the linear MC-RR was divided into tetrapeptide as another intermediate product. The tetrapeptide was finally degraded into Adda (Imanishi et al., 2005). The MC-RR biodegradation pathways by Sphingomonas sp. CBA4 would start by demethylating MC-RR, affording the intermediate product, which is finally biodegraded within 72 hrs (Amé et al., 2006). However, whether the biodegradability and pathways of MC-RR by other strains including Sphingomonas sp. are different, and how they contribute to the fate of algae toxins in natural freshwaters are still poorly understood.

In the present study, we isolated a strain Sphingopyxis sp. USTB-05 from Lake Dianchi, which showed high ability in degrading MC-RR. Its enzymatic degradation pathways on MC-RR were determined. Both intermediate and final degradation products were identified using a combination of HPLC, LC-MS and MALDI-TOF MS.

\section{Materials and methods}

\subsection{Isolation of bacterium}

The strain for the biodegradation of MC-RR was isolated from the sediment samples collected from Lake Dianchi. Five gram of sediment samples were re-suspended in sterilized water for $2 \mathrm{hr}$. The supernatant was used as inoculums and subjected to medium containing $(1 \mathrm{~L}$ distilled water): $1.0 \mathrm{~g} \mathrm{MgSO}_{4} \cdot 7 \mathrm{H}_{2} \mathrm{O}, 0.5 \mathrm{~g} \mathrm{KH}_{2} \mathrm{PO}_{4}, 4.0$ $\mathrm{g} \mathrm{K}_{2} \mathrm{HPO}_{4}, 1.0 \mathrm{~g} \mathrm{NaCl}, 20 \mathrm{mg} \mathrm{CaCl}, 5 \mathrm{mg} \mathrm{FeSO}_{4}$, $5 \mathrm{mg} \mathrm{ZnCl}_{2}, 5 \mathrm{mg} \mathrm{MnCl}_{2} \cdot 4 \mathrm{H}_{2} \mathrm{O}$, and $0.5 \mathrm{mg} \mathrm{CuCl}$. The medium was sterilized before use and the $\mathrm{pH}$ was adjusted to 7.0. MC-RR was added as the sole carbon and nitrogen source at the initial concentration of $50 \mathrm{mg} / \mathrm{L}$. The mixture was incubated for 3 days at $30^{\circ} \mathrm{C}$ in 50 $\mathrm{mL}$ sterile flasks. After three subcultures were prepared by transferring $2.5 \%(\mathrm{~V} / \mathrm{V})$ of the starting inoculums to another flask containing medium with MC-RR, the incubated inoculums were spread on a solid medium, in which $1 \%$ agar $(V / V)$ was added to medium. After several days, different types of colonies were isolated and transferred to medium containing MC-RR $(50 \mathrm{mg} / \mathrm{L})$ to determine their biodegradability. After 3 days of incubation, the solution was centrifuged, and the concentration of MC-RR in the supernatant was measured. Among 7 isolated strains, the one that had the highest biodegradability was incubated in axenic medium

\subsection{Identification of strain}

The isolated strain was identified using $16 \mathrm{~S}$ rDNA analysis with Blast. 16S rDNA was selectively amplified with PCR (Eppendorf-5331) for a total of 30 cycles at $94^{\circ} \mathrm{C}$ for $1 \mathrm{~min}$, then $50^{\circ} \mathrm{C}$ for $1 \mathrm{~min}$ and finally $72^{\circ} \mathrm{C}$ for $3 \mathrm{~min}$. The upstream primer was 5'AGAGTTTGATCATGGCTCAG-3' and the downstream primer was 5'-CTACGGTTACCTTGTTACGAC-3'. The amplified DNA was sent to the Bejing Sunbiotech Co. (China) for sequencing. A multiple alignment was obtained and a phylogenetic tree was constructed according to the neighbor-joining method by Clustal software (Saitou and Nei, 1987).

\subsection{MC-RR}

Standard MC-RR (95\% purity, molecular weight (MW) 1038.2) was purchased from Sigma Chemical Co., USA, and used to test the biodegradation of MC-RR by enzymes of the strain and used as a standard to establish the calibration curve. For the biodegradation kinetic experiment where large amount of MC-RR was needed, the extracted MC-RR with the purity of $7.0 \%$ from cyanobacterial cells collected from Dianchi Lake was used. The content of MC-RR in dry cyanobacterial cells was $1.3 \mathrm{mg} / \mathrm{g}$. The extraction method of MC-RR was described elsewhere (Zhang et al., 2004; Yan et al., 2004b).

\subsection{Preparation of strain and its intracellular enzyme}

After 3 days of incubation, cells of the strain were harvested by centrifugation at $12,000 \mathrm{r} / \mathrm{min}$ for $10 \mathrm{~min}$ and washed three times with $50 \mathrm{mmol} / \mathrm{L}$ potassium phosphate buffer ( $\mathrm{pH}$ 7.0). Then the cells were resuspended using potassium phosphate buffer to make a stock solution containing $0.81 \mathrm{mg}$ cells $/ \mathrm{mL}$ (dry weight) and stored at $-18^{\circ} \mathrm{C}$. This strain solution was used for the biodegradation kinetic experiment.

To obtain the intracellular enzyme, $26 \mathrm{mg}$ cells (dry weight) harvested were resuspended in $20 \mathrm{~mL}$ potassium phosphate buffer solution and disrupted using an ultrasonic disruptor with an output power of $600 \mathrm{~W}$ for $15 \mathrm{~min}$ at $4{ }^{\circ} \mathrm{C}$. The cell debris was removed by centrifugation at 18,000 $\mathrm{r} / \mathrm{min}$ for $20 \mathrm{~min}$, and the supernatant was used as the intracellular enzyme in MC-RR biodegradation pathways studies and stored at $-18^{\circ} \mathrm{C}$.

\subsection{Biodegradation kinetic}

Cells of the strain $(0.0015 \mathrm{mg})$ were added to a 50 $\mathrm{mL}$ flask containing $15 \mathrm{~mL}$ potassium phosphate buffer $(50 \mathrm{mmol} / \mathrm{L})$ in the presence of $50.2 \mathrm{mg} / \mathrm{L} \mathrm{MC}-\mathrm{RR}$. The flask was shaken at $150 \mathrm{r} / \mathrm{min}$ and at $30^{\circ} \mathrm{C}$. At the reaction time of $0,1,2$ and 3 days, aliquot samples were taken and centrifuged at $12,000 \mathrm{r} / \mathrm{min}$ for $10 \mathrm{~min}$. Concentration of MC-RR in the supernatant was measured using high performance liquid chromatography (HPLC, Shimiz LC-10A, Shimdzu Co., Japan). The experiments were conducted in duplicates and the average values were used for analysis. A bacterial-free medium was used as a control. 


\subsection{Enzymatic degradation pathway}

In a $5 \mathrm{~mL}$ centrifuge tube, $15 \mathrm{mg} / \mathrm{L} \mathrm{MC-RR}$ and 38.4 $\mathrm{mg} / \mathrm{L}$ (protein content) intracellular enzyme were prepared in potassium phosphate buffer. The total reaction volume was $1 \mathrm{~mL}$. The tube was shaken at $150 \mathrm{r} / \mathrm{min}$ and at $30^{\circ} \mathrm{C}$. Samples $(150 \mu \mathrm{L})$ were taken from the reaction vessel at 0, 20, 60, 120, 300 and $1440 \mathrm{~min}$. Hydrochloric acid (1\%, $V / V)$ was added to the samples to stop the biodegradation reactions. The samples were measured using HPLC.

In order to identify the intermediate products, $0.5 \mathrm{~mL}$ of samples were taken at 20 and 300 min from another duplicated reaction vessel, which was concentrated using $\mathrm{C} 18$ solid-phase extraction cartridge (Waters, OASIS ${ }^{\mathrm{TM}} \mathrm{HLB}$, USA, $30 \mathrm{mg} / \mathrm{mL}$ ). Then methanol was used to elute the concentrated products with the rate of $1 \mathrm{~mL} / \mathrm{min}$. The elution was analyzed using liquid chromatography tandem one mass spectrometry (LC-MS, API-3000, Applied Biosystems, USA) to determine the molecular weight (MW) of parent MC-RR and its degradation products.

To further confirm the MW of the final product that cannot be identified using LC-MS in the previous procedures, a solution of mobile phase $(0.3 \mathrm{~mL})$ was collected immediately after target peaks appeared in UV chromatogram. The collected solution was dried with nitrogen to remove the acetonitrile contained in the mobile phase. Solids obtained (containing MC-RR and its degradation products) were dissolved with distilled water, and analyzed using matrix-assisted laser desorption/ionization time-offlight mass spectrometry (MALDI-TOF MS, BIFLEX III, Bruker Inc., USA).

\subsection{Analysis methods}

For MC-RR analysis, HPLC was operated at $239 \mathrm{~nm}$. The mobile phase was $40 \%$ (volume percent) acetonitrilewater solution containing $0.03 \%$ (volume percent) of trifluoroacetic acid. The flow-rate was $1.0 \mathrm{~mL} / \mathrm{min}$ and the injection amount was $20 \mu \mathrm{L}$. A Waters Bondapak C18 column $(300 \times 3.9 \mathrm{~mm})$ was used to separate MC-RR and its degradation products.

A 3-micron YMC ODS AQ analytical column from Waters Corp. (USA) was used in the chromatographic measurement in LC-MS analysis. For LC detection, the analysis method was the same as that of HPLC. For MS detection, precursor ions for samples and internal standards were determined from mass spectrum obtained during infusion into the API-3000 mass spectrometer. Using API turbo ionspray (TISP) source, the mass spectrometer was operated in the positive ionization mode with the collision gas off.

For MALDI-TOF MS analysis, the instrument was equipped with a nitrogen laser operating at $337 \mathrm{~nm}$, and a two-state ion source operating in the delayed extraction mode. MALDI-TOF MS was operated in CCA positive ionization mode. Briefly, $2 \mu \mathrm{L}$ of a saturated solution of a-cyano-4-hydroxycinnamic acid (acetonitrile/0.1\% trifluoroacetic acid, 3:2, $V / V$ ) was mixed with $2 \mu \mathrm{L}$ of enzymatic biodegradation samples. The preparation of the enzymatic biodegradation samples was described in the above section. Afterward, $2 \mu \mathrm{L}$ of the mixture was applied to the sample plate, and air-dried at $24^{\circ} \mathrm{C}$. Measurements were performed at an acceleration voltage of $20 \mathrm{kV}$ using reflector mode, allowing the determination of monoisotopic mass values. Each spectrum refers to the sum of 100-200 individual laser shots.

\section{Results and discussion}

\subsection{Strain identification}

16S rDNA sequence homology searches using the basic local alignment search tool (BLAST) system corroborated the positioning of USTB-05 in genus Sphingopyxis sp. The neighbor-joining phylogenetic tree is shown in Fig. 1. The close relatives were proved to be Sphingomonas sp. and Novosphingobium sp. The homology percentage of $16 \mathrm{~S}$ rRNA in the strain USTB-05 and Sphingopyxis sp. C-1 was $96 \%$. Although it is reported that Sphingomonas sp. ACM3962, 7YC, CBA4 and Y2 are able to degrade MCs (Jones et al., 1994; Ishii et al., 2004; Amé et al., 2006; Tsuji et al., 2006), the position of the strain in the tree was distinctively separated from the clusters of them. This indicated that USTB-05 isolated in this study may be a new species of Sphingopyxis for MCs degradation. The complete sequences of the 1453 bp 16S rDNA fragment from this strain had been deposited in the GenBank database under accession number EF607053.

\subsection{Microbial biodegradation kinetics}

The kinetic curve of the biodegradation of MC-RR by Sphingopyxis sp. USTB-05 is shown in Fig. 2. After one day of lag phase, the concentration of MC-RR decreased rapidly, and the initial MC-RR of $50.2 \mathrm{mg} / \mathrm{L}$ was completely removed within 3 days, while the MC-RR in control flask remained relatively constant. The average biodegradation rate of MC-RR by the strain was $16.7 \mathrm{mg} / \mathrm{L}$ per day which showed that the strain had a strong ability in the degradation of MC-RR.

\subsection{Enzymatic degradation pathway}

Different degradation products of MC-RR at 0,20 , 60, 300, and $1440 \mathrm{~min}$ were clarified based on the peak position in Fig. 3. For the sample collected at $0 \mathrm{~min}$, the peak at 5.3 min was MC-RR because it appeared at the retention time of standard MC-RR (Yan et al., 2002). The first peak at 3.0 min was due to an impurity of the MCRR solution. For the sample collected at $20 \mathrm{~min}$, the peak of MC-RR decreased with reaction time, and a new peak I at $3.8 \mathrm{~min}$ was observed. For the sample collected at 120 min, another peak II at 8.10 min was observed while the peak of MC-RR disappeared. After reached a maximum at $60 \mathrm{~min}$, peak I decreased and disappeared after $24 \mathrm{hr}$, indicating that it was an intermediate product, whereas, peak II increased with time and kept constant after $24 \mathrm{hr}$, indicating that it was the final biodegradation product.

To identify the degradation products, $0.5 \mathrm{~mL}$ samples were taken from another biodegradation reaction vessel at reaction time of 20 and $300 \mathrm{~min}$. Because MC-RR, peak 


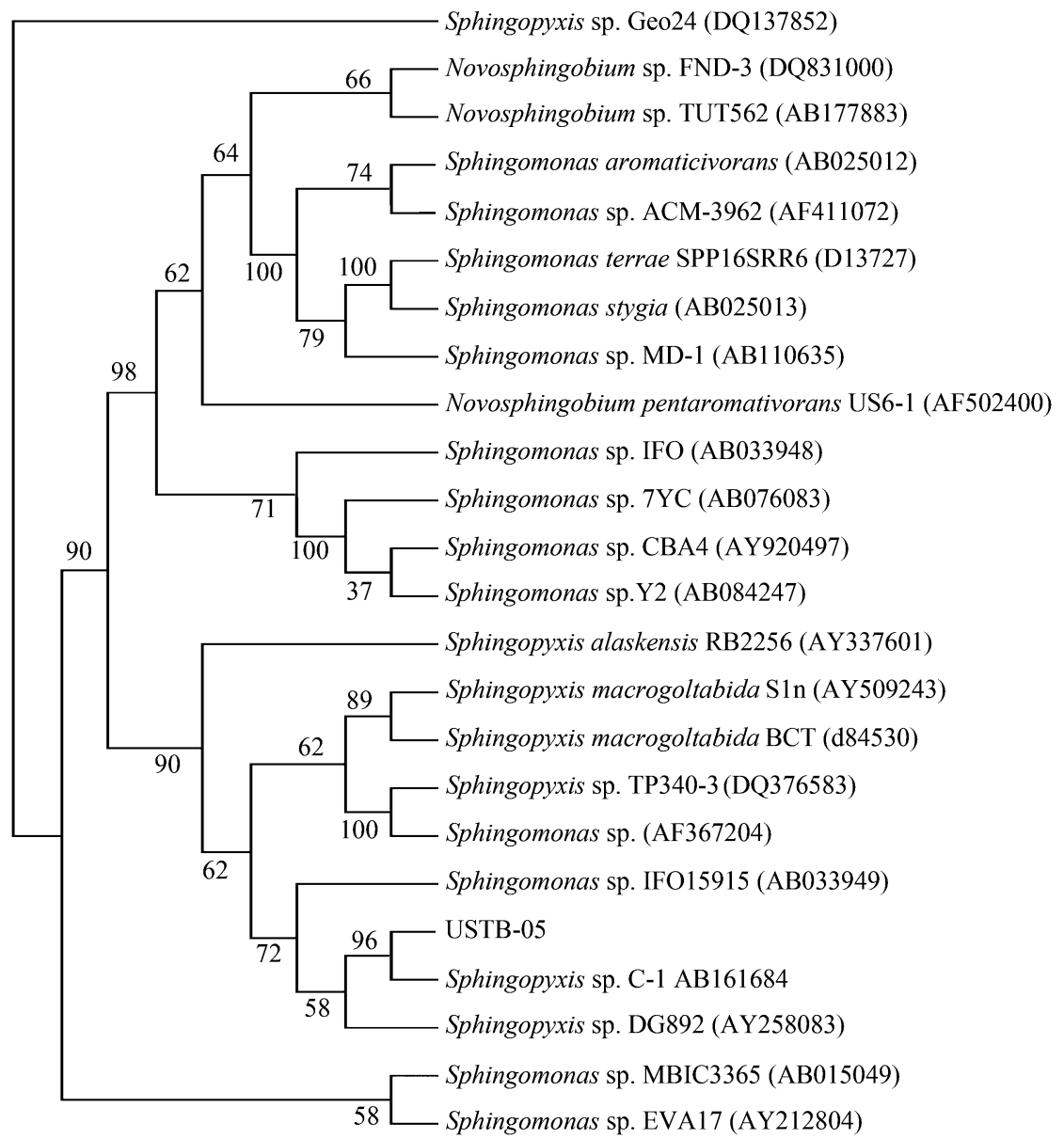

Fig. 1 Neighbor-joining phylogenetic tree showing the position of the strain based on 16S rDNA gene sequence. Database accession numbers of reference sequences are shown after the strain names. The value on each branch is the estimated confidence limit (expressed as a percentage) for the position of the branch as determined by a bootstrap analysis.

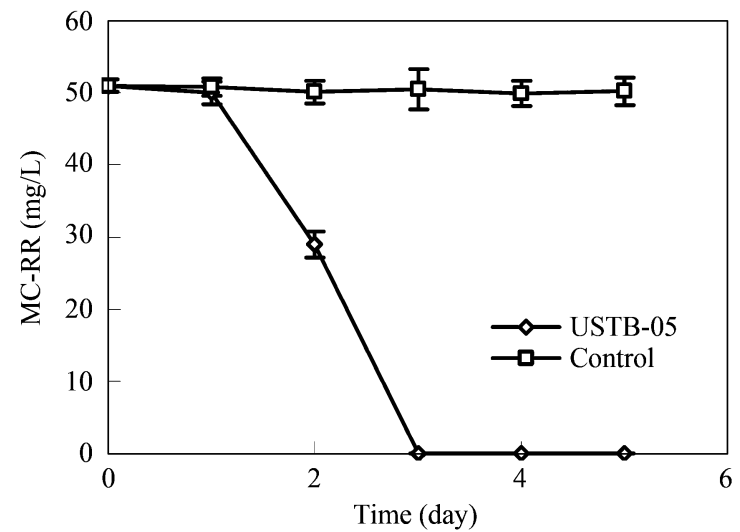

Fig. 2 Bacterial biodegradation kinetics of MC-RR by Sphingopyxis sp. USTB-05.

I and peak II were baseline separated with the retention times of 5.3, 3.8 and $8.0 \mathrm{~min}$, respectively. Samples collected at different reaction times were mixed together to measure the intermediate and final degradation products contained in peak I and II by LC-MS. Results are presented in Fig. 4.

Four distinct peaks were observed in total ion chromatogram (TIC) (Fig. 4a). Based on the retention time in
UV chromatogram (Fig. 3 and Fig. 4b), the second and third peaks marked with column in TIC corresponded to MC-RR (retention time $4.7 \mathrm{~min}$ ) and peak I (retention time $3.4 \mathrm{~min}$ ), respectively. The MS spectrum of MC-RR in Fig. $4 \mathrm{c}$ revealed a major ion at $\mathrm{m} / \mathrm{z} 1038.7$, corresponding to the protonated molecular ion $[\mathrm{M}+\mathrm{H}]^{+}$. The MS spectrum for peak I (retention time $3.58 \mathrm{~min}$ ) showed four ion peaks at $m / z 1056.9,529.1,905.6,453.5$ (Fig. 4d). Due to the different degrees of protonation, ion peaks at $\mathrm{m} / \mathrm{z} 1056.9$ and 529.1 represented one product, corresponding to the protonated molecular ion $[\mathrm{M}+18+\mathrm{H}]^{+}$and $[\mathrm{M}+18+2 \mathrm{H}]^{2+}$, respectively. Ion peaks at $m / z 905.6$ and 453.5 represented another product, corresponding to the protonated molecular ion $[\mathrm{M}-133+\mathrm{H}]^{+}$and $[\mathrm{M}-133+2 \mathrm{H}]^{2+}$, respectively.

Since the final products contained in peak II can only be detected in UV chromatogram (Fig. 4b), but not clearly in TIC spectrum (Fig. 4a), sample of $24 \mathrm{hr}$ was further analyzed using MALDI-TOF-MS. Results in Fig. 5 showed three ions with $m / z$ of $991.7,1007.8$ and 1021.8, respectively.

Based on the above analysis, the ion with $\mathrm{m} / \mathrm{z}$ 1056.9 contained in Peak I had a MW 18 Da which was higher than that of MC-RR. MC-RR has the structure of cyclo-D-alanine-arginine-D-erythro- $\beta$-methyl- 

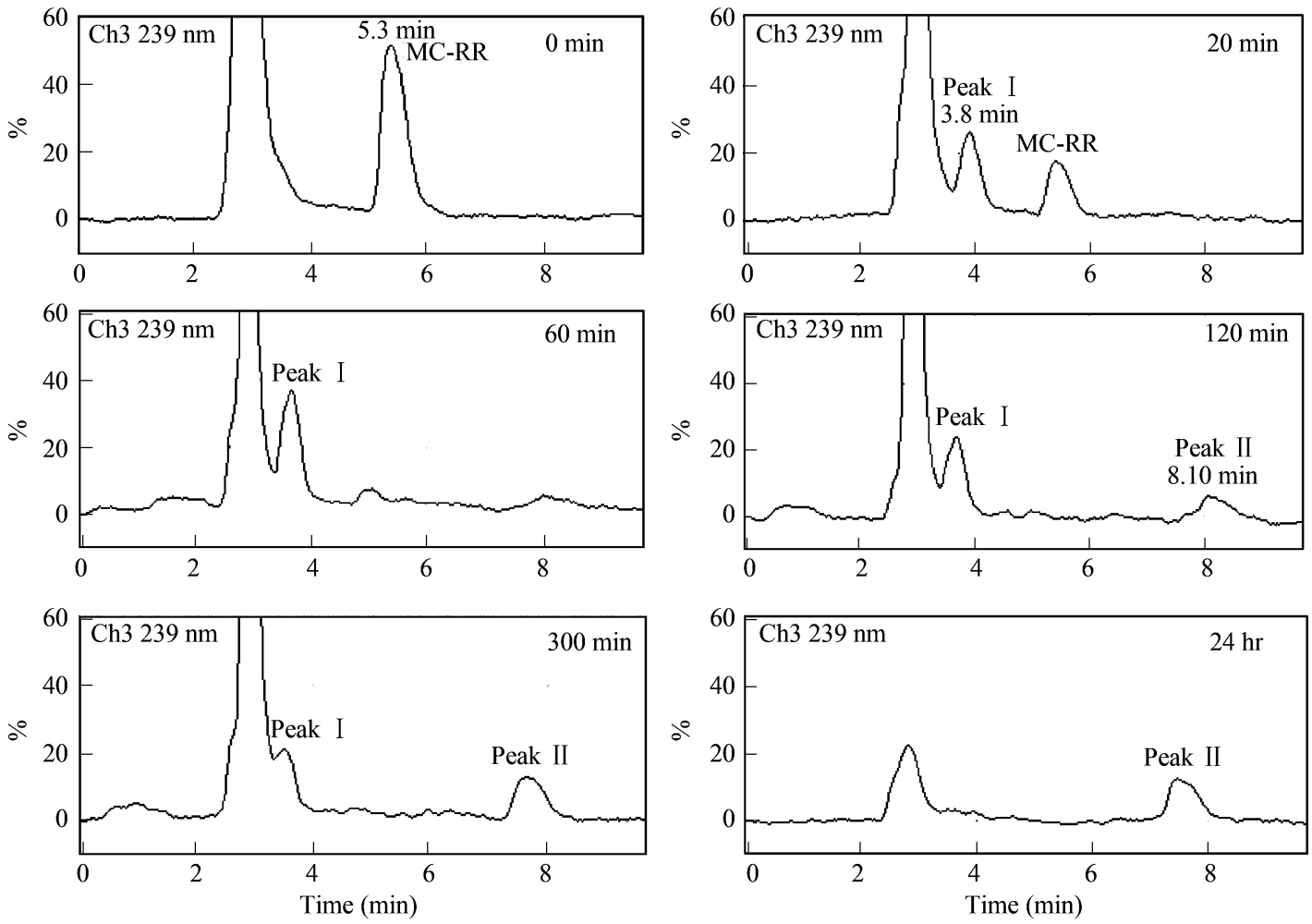

Fig. 3 HPLC profile of the biodegradation of MC-RR catalyzed by intracellular enzymes of Sphingopyxis sp. USTB-05.

D-isoaspartic acid-arginine-Adda-D-isoglutamic acid-Nmethyldehydroalanine (Fig. 6). Adda is a characteristic $\beta$-amino acid (2S, 3S, 8S, 9S)-3-amino-9-methoxy-2,6,8trimethyl-10-phenyldeca-4(E), 6(E)-dienoic acid, which is essential to the toxicity of MC-RR. Previous studies revealed that Adda-Arg was the bond that was easily attacked during the enzymatic degradation by many bacteria (Bourne et al., 1996, 2001; Imanishi et al., 2005). Ion with $\mathrm{m} / \mathrm{z} 1056.9$ may thus be derived from MC-RR by opening the ring through breaking the Adda-Arg bond and combining one hydrogen on the $\mathrm{NH}_{2}$ group of Adda and a hydroxyl on the carboxyl group of arginine. MC-RR was turned into a linear $\left(\mathrm{NH}_{2}\right.$-Adda-Glu-Mdha-Ala-ArgMeAsp-Arg-OH) as intermediate product-a (Fig. 6). The processes lead a higher MW of product-a (18 Da) compare to MC-RR. Ion with $\mathrm{m} / \mathrm{z}, 905.6$ had MW 133 Da lower than that of MC-RR, which coincided with the loss of the terminal phenylethylmethoxy group and the amino $\mathrm{NH}_{2}$ group from the Adda after Adda-Arg bond breaking. This is a common loss fragment of MCs due to the radical fragmentation rearrangement (Namikoshi et al., 1992). The ion with $\mathrm{m} / \mathrm{z} 1021.8$ had a MW $36 \mathrm{Da}$ which was lower than that of product-a, corresponding to two $\mathrm{H}_{2} \mathrm{O}$ loss from product-a. Studies with ${ }^{18} \mathrm{O}$-labeled peptides showed that dehydration can occur from the free carboxylic groups of the participant amino acids, hydroxyl substituted bonds and even the backbone of the peptides (Antoniou et al., 2008). The most basic sites and therefore easily protonated sitse in MC-LR are the guanidine portion of arginine, as supported by computation studies for the lowest energy conformation of the singly protonated MC-LR (Yuan et al., 1999). Thus, product-a may go through two dehydrations arising from the combination of two hydrogen of amino group on arginine with adjacent hydroxyl on carboxy to form the linear MC-RR with the two small peptide rings as the final product-b (Fig. 6). The peaks of other two ions with $\mathrm{m} / \mathrm{z} 1007.8$ and 991.7 were not separated from that of product-b in UV chromatogram, which indicated that they may be the fragments of product-b due to the radical fragmentation rearrangement. Because the ion with $\mathrm{m} / \mathrm{z} 1007.8$ had lower MW (14 Da) than product-b, a demethylation might happen. The previous studies reported that the methoxy group of the Adda amino acid can be easily protonated, where the fragmentation is easy to happen (Yuan et al., 1999). Ion with $m / z 1007.8$ thus might be formed by the demethylation from methoxy group of Adda. Ion with $\mathrm{m} / \mathrm{z} 991.7$ had a lower MW (30 Da) than product-b, except one $\mathrm{CH}_{3}$ loss, and one $\mathrm{NH}_{2}$ loss from Adda group may be happened. The structure of product-b was gotten by conjecture based on the above results. More studies should be carried out to characterize the structure of product-b by other methods such as nuclear magnetic resonance. The possible degradation pathways of MC-RR by Sphingopyxis sp. USTB-05 are illustrated in Fig. 6.

\subsection{General impact in natural lakes}

Biodegradation is one of the essential processes for the reduction of MCs in natural eutrophic lakes and reservoirs. MCs degrading bacteria are distributed all over the world. Studies on the enzymatic pathways of various isolated stains for MCs are important to understand their fate in natural environment. Because of floating, algae toxins release is often subject to aerobic biodegradation in time scale of minutes to hours in the water column, which 

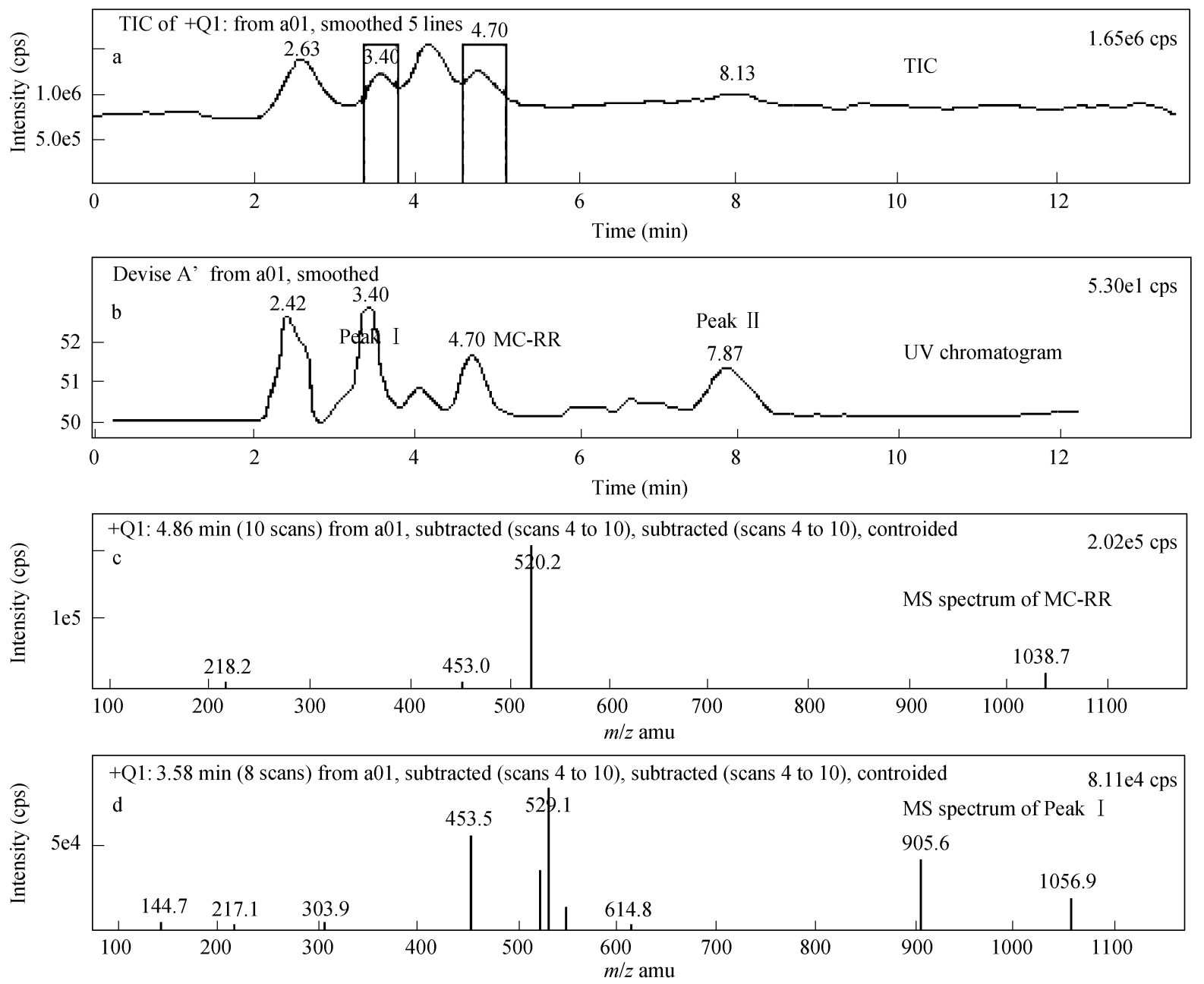

Fig. 4 LC/MS profile of MC-RR and its biodegradation products. (a) total ion chromatogram (TIC); (b) UV chromatogram; (c) MS spectrum for MC-RR; (d) MS spectrum for peak I.

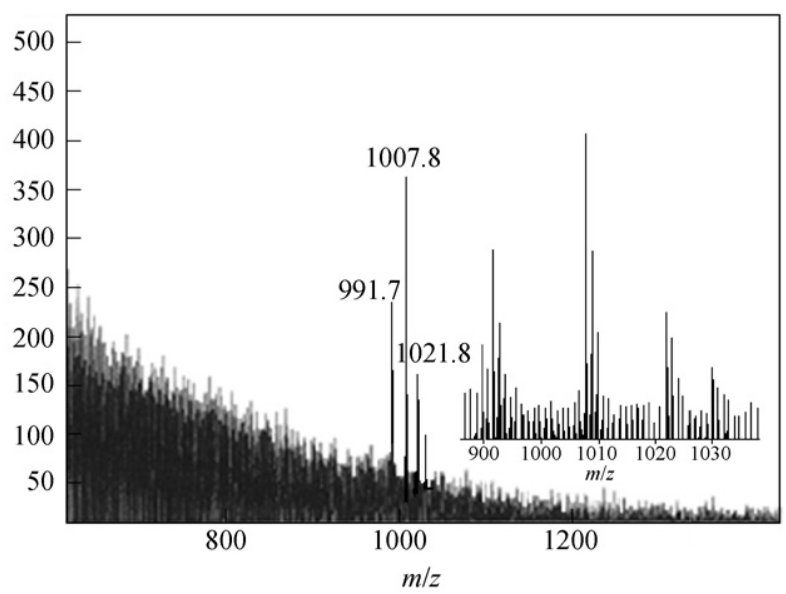

Fig. 5 MALDI-TOF MS profile of final biodegradation products of MCRR catalyzed by the enzymes of Sphingopyxis sp. USTB-05.

may greatly change their molecular structure and toxicity. Because of the complexity of natural bacteria in the natural lakes, detail information on biodegradation pathways are often obtained through studies on pure strains. Up to now, as to the biodegradation pathways of MC-
RR, studies are focused on two strains, i.e., Sphingomonas sp. B-9 and CBA4. The mechanisms of Adda-Arg bond breaking for Sphingomonas sp. B-9 and demethylation for Sphingomonas sp. CBA4 were found in the enzymatic degradation processes of MC-RR. Here, our study showed that the degradation pathways of MC-RR by the strain Sphingopyxis sp. USTB-05 were different from the two strains mentioned above. Except for the Adda-Arg bond breaking, the mechanism of dehydration was involved in the MC-RR enzymatic degradation processes by Sphingopyxis sp. USTB-05 which made the structure of the final product different from that reported in the previous studies (Imanishi et al., 2005; Amé et al., 2006). The fact, MCRR biodegradation mechanisms may vary with different bacteria implies that the same MC-RR may go through different biodegradation pathways and hence different fate in various lakes. Adda-Arg ring opening is essential for the detoxification (Bourne et al., 1996). Studies should be taken into consideration for the risk assessment of MC-RR in natural lakes. Studies on cooperative and antagonistic effects between different strains are also needed for understanding biodegradation pathways of MC-RR and their impacts on the toxicity in the aquatic environment. 


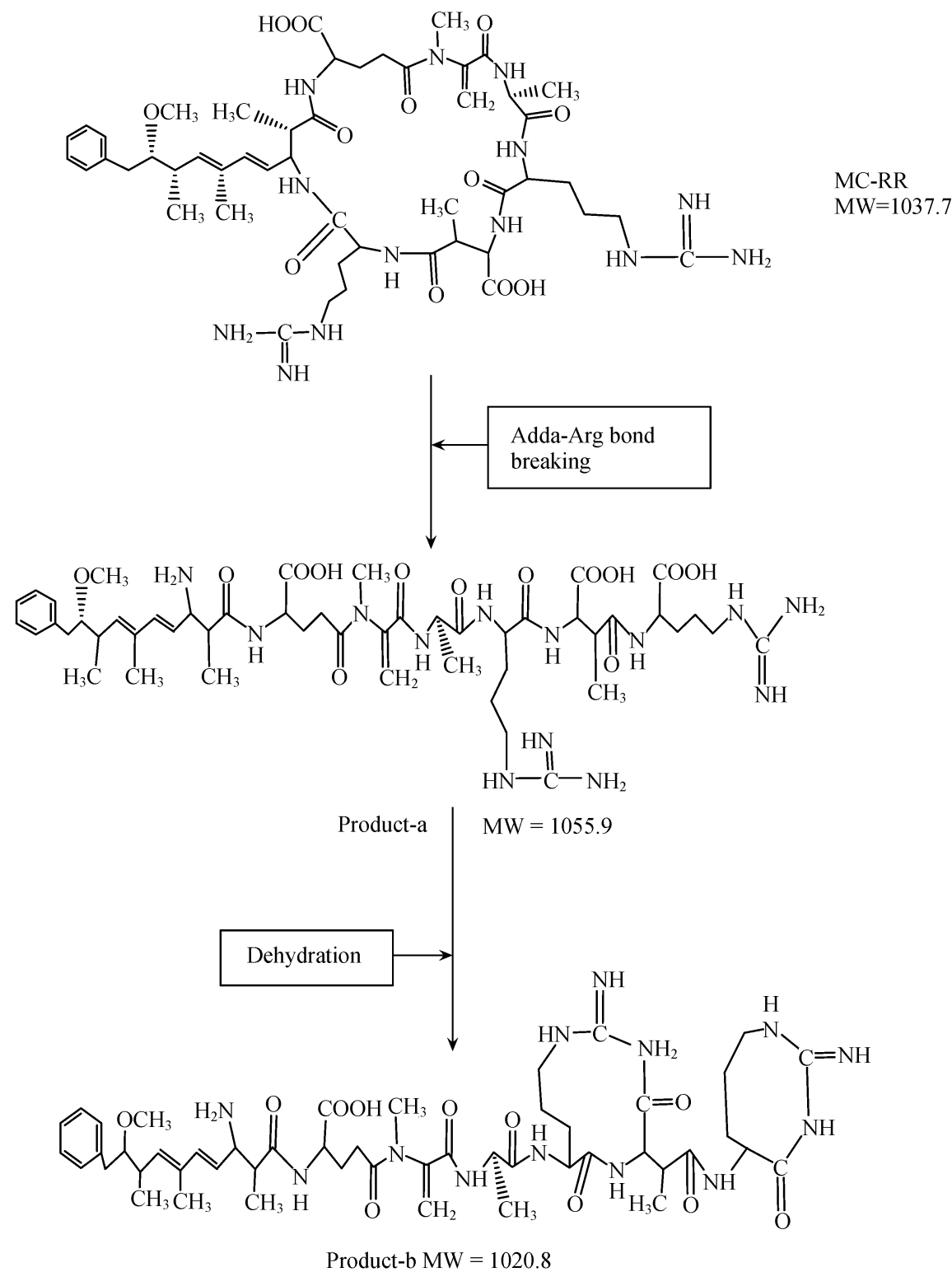

Fig. 6 Proposed biodegradation pathways of MC-RR by the enzymes of Sphingopyxis sp. USTB-05.

\section{Conclusions}

(1) Sphingopyxis sp. USTB-05 isolated from Lake Dianchi has a strong ability in the biodegradation of MC-RR at the rate of $16.7 \mathrm{mg} / \mathrm{L}$ per day.

(2) In the enzymatic biodegradation pathways of MCRR by Sphingopyxis sp. USTB-05, the Adda-Arg peptide bond of MC-RR was cleaved firstly to form linear one as the intermediate product (product-a), and then dehydrated by combining two hydrogen of amino group on arginine with adjacent hydroxyl on carboxy to form the final degradation product-b.

\section{Acknowledgments}

This work was supported by the Chinese National Key Project for Basic Research (No. 2008CB418105), the National Natural Science Foundation of China (No. 20621703, 20477050), and the Important-DirectionProject funded by the Chinese Academy of Sciences.

\section{References}

Amé M V, Echenique J R, Pflugmacher S, Wunderlin D A, 2006. Degradation of Microcystin-RR by Sphingomonas sp. CBA4 isolated from San Roque reservoir (CórdobaArgentina). Biodegradation, 17: 447-455.

Antoniou M G, Shoemaker J A, Cruz A A, Dionysiou D D, 2008. LC/MS/MS structure elucidation of reaction intermediates formed during the $\mathrm{TiO}_{2}$ photocatalysis of microcystin-LR. Toxicon, 51: 1103-1118.

Bourne D G, Jones G J, Blakeley R L, Jones A, Negri A P, Riddles P, 1996. Enzymatic pathway for the bacterial degradation of the cyanobacterial cyclic peptide toxin microcystin-LR. Applied and Environmental Microbiology, 62: 4086-4094.

Bourn D G, Riddles P, Jones G J, Smith W, Blakeley R L, 2001. Characterisation of a gene cluster involved in bacterial degradation of the cyanobacterial toxin microcystin LR. Environmental Toxicology, 16(6): 523-534.

Chen W, Song L R, Peng L, Wan N, Zhang X M, Gan N Q, 2008. Reduction in microcystin concentrations in large and shallow lakes: Water and sediment-interface contributions. 
Water Research, 42: 763-773.

Dawson R M, 1998. The toxicology of microcystins. Toxicon, 36: 953-962.

He H S, Yan H, Zhou J, Xiao B Q, Lu L, 2006. Characterization of enzymatic degradation of microcystins by a new isolated bacterium. Environmental Sciences, 27: 1171-1175.

Ho L, Gaudieuxb A L, Fanok S, Newcombea G, Humpagea A R, 2007. Bacterial degradation of microcystin toxins in drinking water eliminates their toxicity. Toxicon, 50: 438441.

Imanishi S, Kato H, Mizuno M, Tsuji K, Harada K, 2005. Bacterial degradation of microcystins and nodularin. Chemical Research in Toxicology, 18: 591-598.

Ishii H, Nishijima M, Abe T, 2004. Characterization of degradation process of cyanobacterial hepatotoxin by a Gram-negative aerobic bacterium. Water Research, 38: 2667-2676.

Jones G J, Bourne D, Blakeley R L, Doelle H, 1994. Degradation of the cyanobacterial hepatotoxin microcystin by aquatic bacteria. Natural Toxins, 2: 228-235.

Jones G J, Orr P T, 1994. Release and degradation of microcystin following algicide treatment of a Microcystis aeruginosa bloom in a recreational lake, as determined by HPLC and protein phosphatase inhibition assay. Water Research, 28: 871-876.

Lemes G A F, Kersanach R, Pinto L S, Dellagostin O A, Yunes J S, Matthiensen A, 2008. Biodegradation of microcystins by aquatic Burkholderia sp. from a South Brazilian coastal lagoon. Ecotoxicology and Environmental Safety, 69: 358365 .

Namikoshi M, Rinehart M K L, Sakai R, 1992. Identification of 12 hepatotoxins from a Homer Lake bloom of the cyanobacteria Microcystis aeruginoaa, Microcystis viridis, and Microcystis wesenbergii: Nine new microcystins. Journal of Organic Chemistry, 57: 866-872

Paerl H W, Fulton R S, Moisander P H, Dyble J, 2001. Harmful freshwater algal blooms, with an emphasis on cyanobacteria. Scientific World Journal, 1: 76-113.

Pan X J, Chang F Y, Shen Y W, Liu Y D, Li D H, Li G B et al., 2006. The correlation between the variation of microcystin content and environment factors in Dianchi Lake. Journal of Lake Sciences, 18: 572-578.

Park H D, Sasaki Y, Maruyama T, Yanagisawa E, Hiraishi A, Kato K, 2001. Degradation of the cyanobacterial hepatotoxin microcystin by a new bacterium isolated from a hypertrophic lake. Environmental Toxicology, 16: 337-343.

Rapala J, Berg K A, Lyra C, Niemi R M, Manz W, Suomalainen
S et al., 2005. Paucibacter toxinivorans gen. nov., sp. Nov., a bacterium that degrades cyclic cyanobacterial hepatotoxins microcystins and nodularin. International Journal of Systematic and Evolutionary Microbiology, 55: 1563-1568.

Saitou N, Nei M, 1987. The neighbor-joining method: A new method for reconstructing phylogenetic trees. Molecular Biology Evolution, 4: 406-425.

Song W H, Bardowell S, O'Shea K, 2007. Mechanistic study and the influence of oxygen on the photosensitized transformations of microcystins (cyanotoxins). Environmental Science $\mathcal{E}$ Technology, 41: 5336-5341.

Takenaka S, Watanabe M F, 1997. Microcystin LR degradation by Pseudomonas aeruginosa alkaline protease. Chemosphere, 34: 749-757.

Tsuji K, Naito S, Kondo F, Ishikawa N, Watanabe M F, Suzuki M et al., 1994. Stability of microcystins from cyanobacteria: effect of light on decomposition and isomerisation. Environmental Science $\mathcal{E}$ Technology, 28: 173-177.

Tsuji K, Setsuda S, Watanuki T, Kondo F, Nakazawa H, Suzuki M et al., 1996. Microcystin levels during 1992-1995 for lakes Sagami and Tsukui-Japan. Natural Toxins, 4: 189-194.

Tsuji K, Asakawa M, Anzai Y, Sumino T, Harada K, 2006. Degradation of microcystins using immobilized microorganism isolated in an eutrophic lake. Chemosphere, 65: 117-124.

Yan H, Pan G, Zhang M M, 2002. Advances in the study of microcystin toxin. Acta Ecologica Sinica, 22: 1968-1975.

Yan H, Pan G, Zou H, Song L R, Zhang M M, 2004a. Effects of nitrogen forms on the production of cyanobacterial toxin microcystin-LR by an isolated Microcystis aeruginosa. Journal of Environmental Science and Health Part A Toxic/Hazardous Substance $\mathcal{E}$ Environmental Engineering, 39: 2993-3003.

Yan H, Pan G, Zou H, Li X L, Chen H, 2004b. Effective removal of microcystins using carbon nanotubes embedded with bacteria. Chinese Science Bulletin, 49: 1694-1698.

Yuan M, Namikoshi A, Otsuki K L, Rinehart K, Sivonen Y, Watanabe M F, 1999. Low-energy collisionally activated decomposition and structural characterization of cyclic heptapeptide microcystins by electrospray ionization mass spectrometry. Journal of Mass Spectrometry, 34: 33-43.

Zhang M M, Pan G, Yan H, Chen H, 2004. A method to extract algae toxin of microcystin-LR. Journal of Environmental Sciences, 16: 694-696.

Zhang W H, Zhang X H, Zhang G M, Xu X Q, 2003. Variation of microcystins in a lake for water supply. Journal of Environmental Science and Health Part A - Toxic/Hazardous Substances $\mathcal{F}$ Environmental Engineering, 38: 2857-2865. 